In Western Australia Grey Kangaroos are strictly preserved in practically the whole of the South-Western Land Division, but no other protection is given to kangaroos.

The fauna of Tasmania is being maintained at a fairly good level. The Platypus has been saved by total protection. The Thylacine is on the verge of extinction although the reward which used to be paid for its destruction has been stopped and there are still thousands of square miles of suitable country for this animal. The reason for its rapid diminution is obscure.

Everywhere the Koala is entirely protected and owing to the great efforts made on its behalf seems on the whole to be increasing. Many colonies have been discovered in New South Wales, one of which has nearly 1,000 animals. Man-made bush fires constitute one of its most serious menaces, though people still cut down trees with koalas in them and take the young.

Breeding of Koalas for release in sanctuaries has been carried out at Taronga Park and elsewhere and it has been found that the correct breeding proportion is about six females to one male.

It seems that the Commonwealth Government has introduced goats on to Macquarie Island, a great bird sanctuary, and that they have already made great inroads into the vegetation. It was suggested at the Conference that a protest should be made and the Commonwealth Government requested that the matter should be reconsidered.

\title{
PROTECTION OF WILD LIFE IN NEW SOUTH WALES
}

In 1948, by Act of Parliament, New South Wales established a Fauna Protection Panel for the care and protection of her native fauna. The Panel consists of 14 members including the Chairman, Mr. F. J. Griffiths, who has the title of Chief Guardian of Fauna. The Deputy Chairman is Mr. E. J. Hallstrom, President of the Taronga Zoological Park Trust. 'The Sydney University is represented by its Professor of Zoology. There is one member representing rural interests. The Linnean Society and Royal Zoological Society are represented. The Wild Life Protection Society of Australia is represented by its Honorary Secretary, Mr. A. A. Strom.

The duties of the Panel are laid down in the Act. Besides the formal one of advice to the Minister, they include educational activities to awaken appreciation of the value of wild life, the 


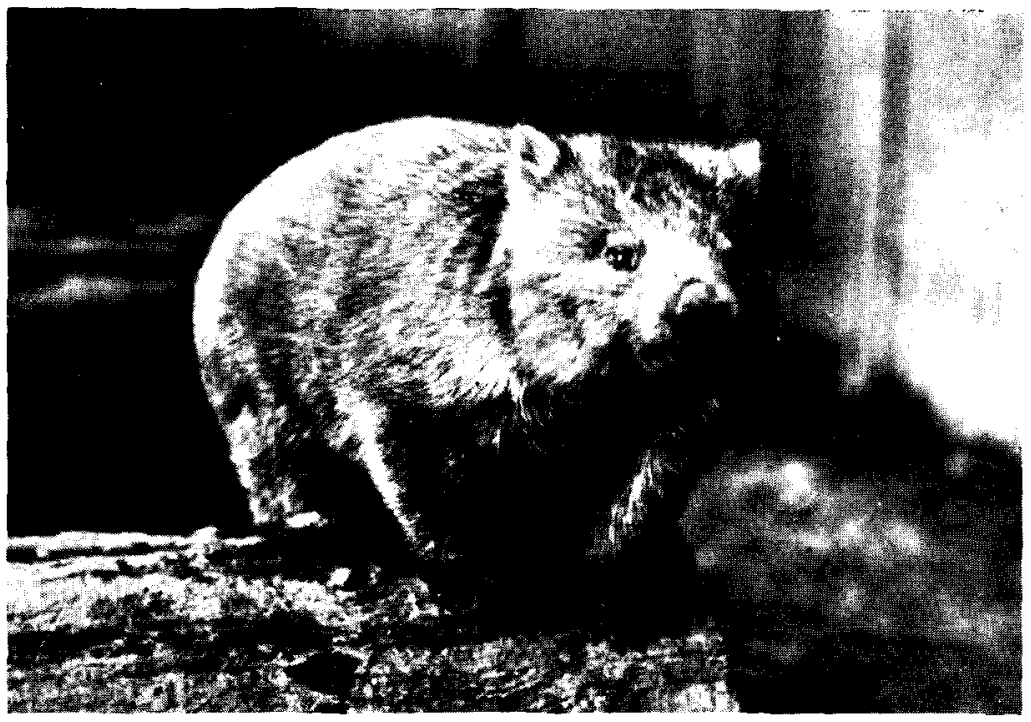

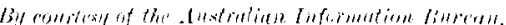

MITCHELISS WOXIBNT.

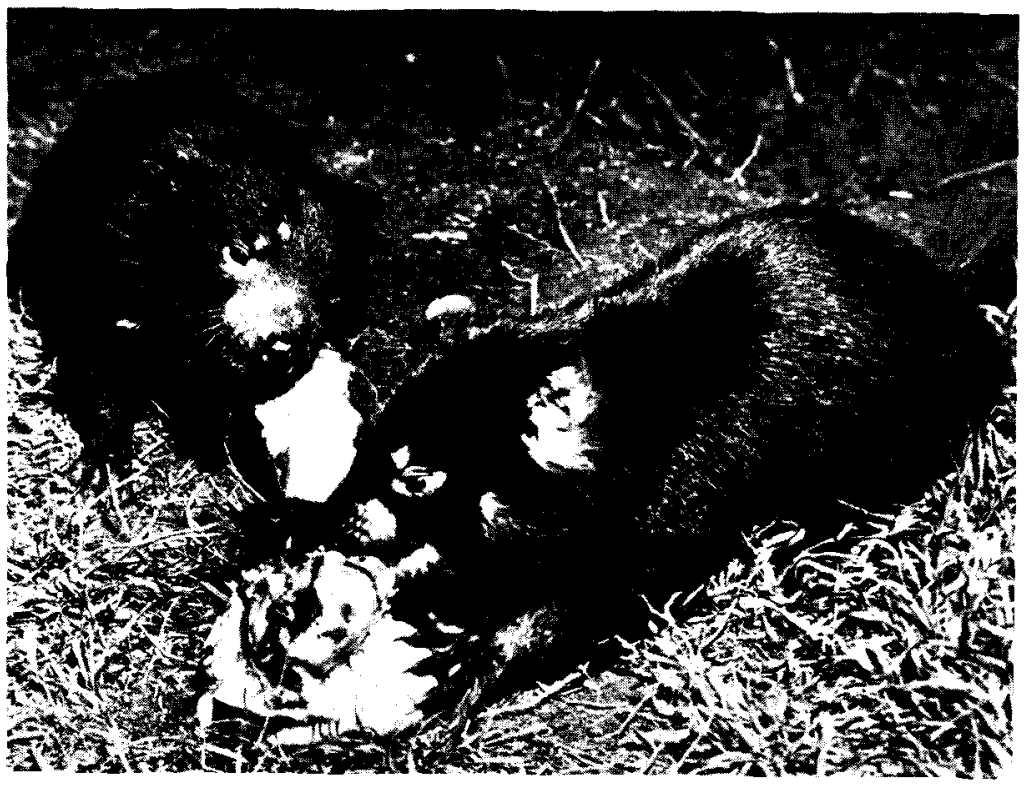

TASULNIAN IDEVII. 

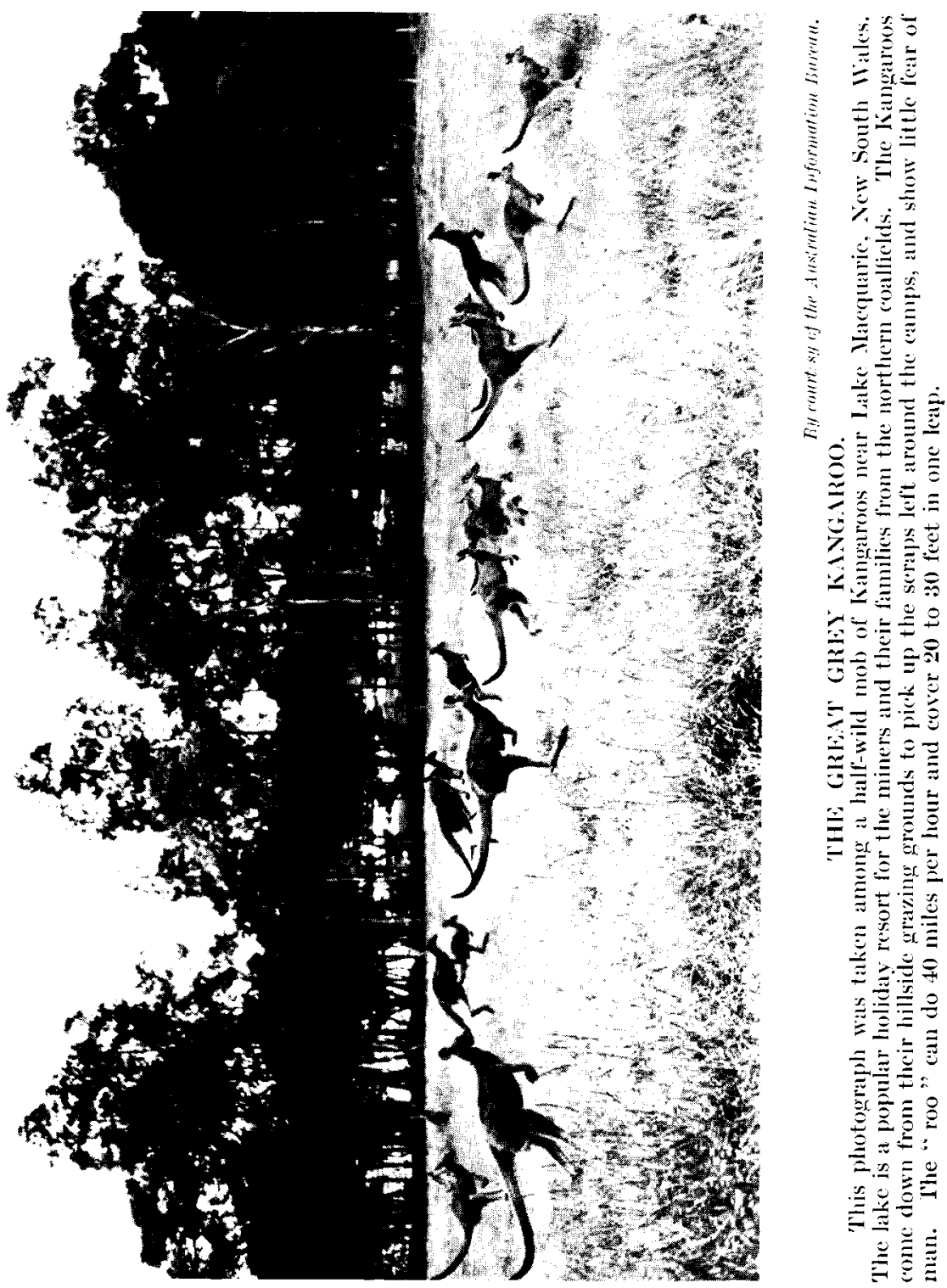


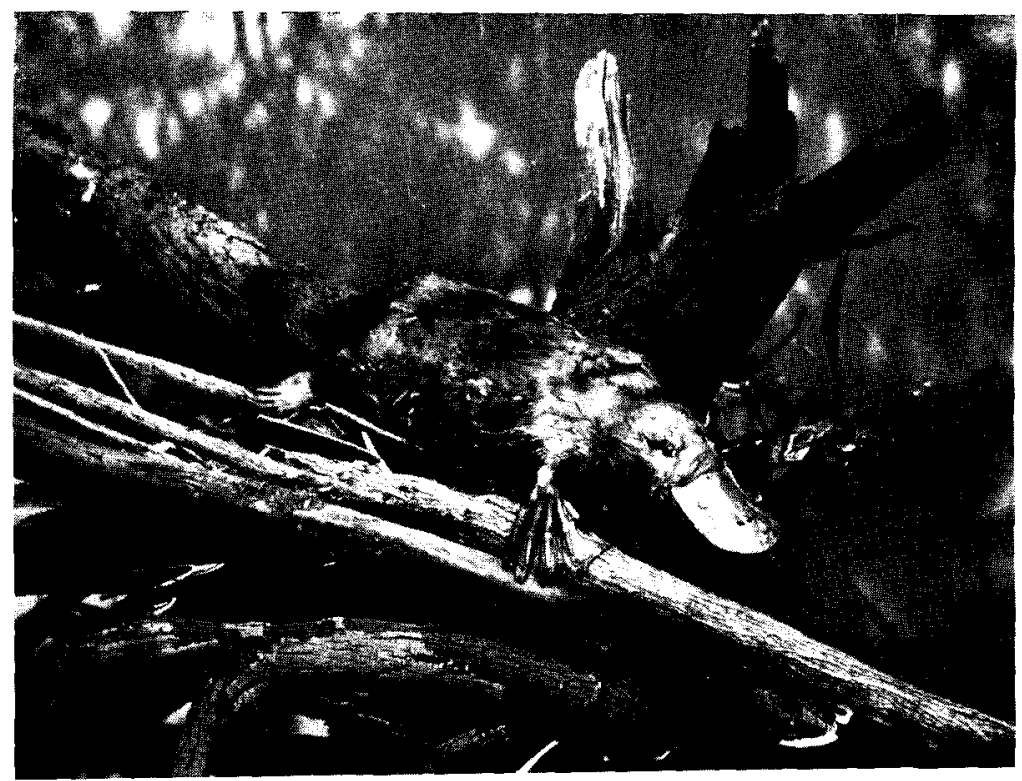

PIATYPIS, SHOWING FORLGOOT.

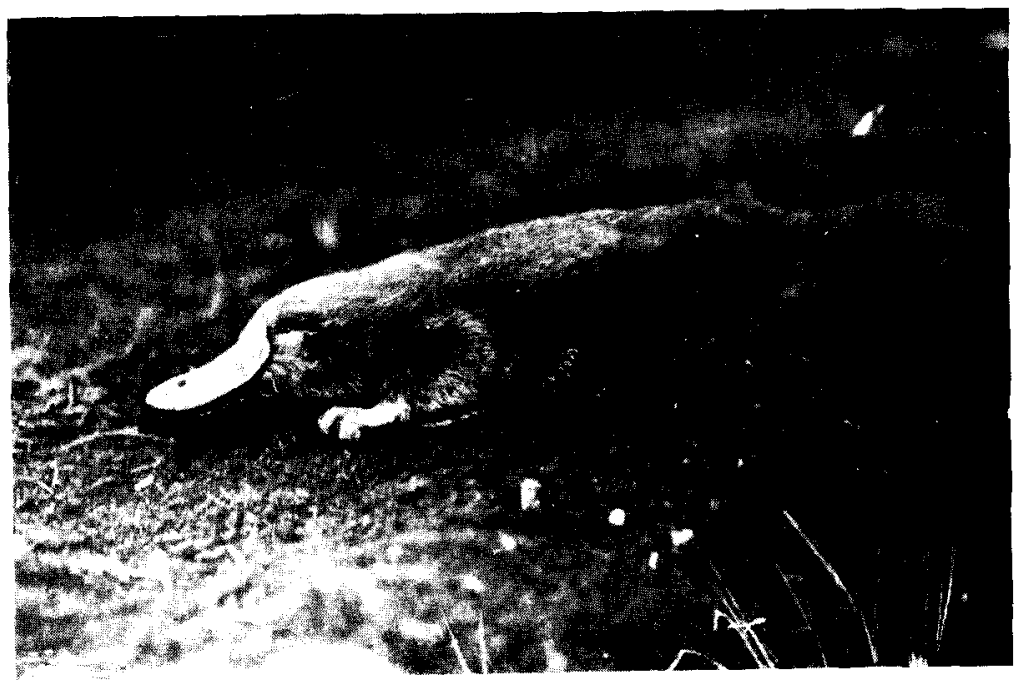

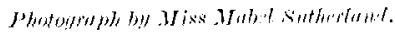
PITYPIS, RINNING ON JTS GXITKIAS. 


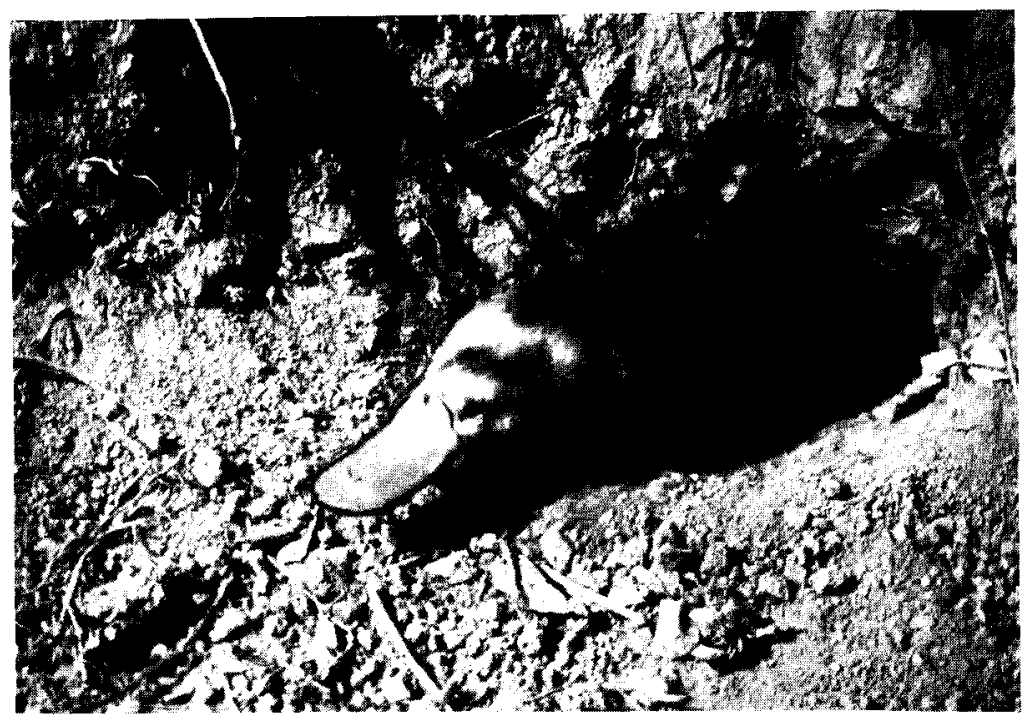

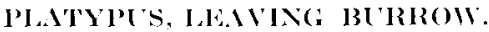

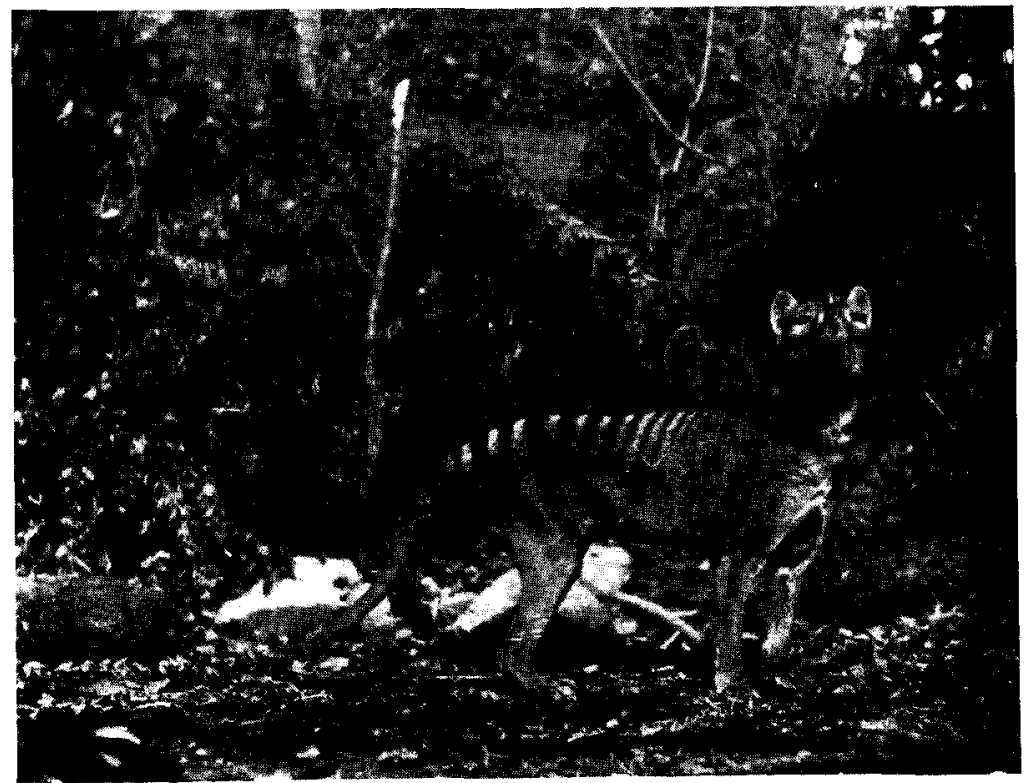

THYLACINE (TISMANIAN WOLF). 
control and management of faunal reserves, the formation of local fauna societies and biological research in connection with the protection of fauna.

The Panel started work on 1st July, 1949, and has sent our Society - of which as a body it is a member-a report on its first twelve months of work. This includes the following.

Education.--Realizing that education must begin with the children the Panel has asked the Education Department to include in the primary school syllabus instruction on Australian animals. This request is now before the Departmental Syllabus Committee. As this requirement presumes knowledge by teachers, the necessary changes in the syllabus of the teachers training colleges are also requested.

Following on reports of the destruction of birds by new Australians, the Panel gave consideration to plans for special measures to be taken to deal with the menace to bird life. The Commissioner of Police has asked all officers of the Police Force to pay particular attention to the matter and wherever possible to give personal advice to new Australians in the requirements of the Fauna Protection Act. Arrangements have been made with the Department of Education for instruction regarding fauna protection to be given to classes conducted for new Australians in some 200 centres. Talks, illustrated by films will be given in migrant centres and camps.

Publicity.- The work of the Panel has been published in daily and weekly newspapers. During the coming year special articles will appear on its educational work.

News of wild life protection and the work of the Panel has been broadcast, great assistance being given by the session "Nature Speaks" sponsored by Hallstroms Pty Ltd.

In the Humane Poster Competition conducted annually by Farmer and Co., Ltd., and the R.S.P.C.A. a "Protect the Koala" section was included, attracting two hundred entries. A display was arranged at the Royal Easter Show of the Bush Fire Committee.

Koala Conservation.-A survey of New South Wales was carried out to discover the strength and whereabouts of colonies of Koalas. The press and radio gave great assistance as did the Forestry Commission, the Departments of Agriculture and Lands and the Police and school teachers. The present distribution of Koalas in the state has been ascertained and although the population has not been accurately determined, the survey has revealed that there are some thousands of Koalas in New South Wales. 
In conjunction with the Ku-ring-gai Chase Trust a site for a Koala reserve has been selected between Bobbin Head and Mount Colah. This site is easy of access and has an abundant supply of food. The Colonial Treasurer has approved a loan of $£ 7,500$ and it is hoped soon to start work on the reserve.

The following is the plan drawn up by the Panel to ensure that the Koala will never become extinct :-

(i) The establishment of an experimental station for the study of the breeding, feeding, and diseases of Koalas. Mr. Hallstrom has generously made available to the Panel his property at Mona Vale and has offered to erect all necessary buildings ; this work is to commence shortly. A small Scientific Committee has been set up under the leadership of Professor Murray.

(ii) The establishment of reserves similar to that proposed for Ku-ring-gai Chase in areas controlled by Trusts or Municipal Authorities.

(iii) The restocking, when the expected increase in Koalas permits, of areas where they have lived in the past, provided that it is reasonably certain that they will not succumb to dogs, foxes, hunger, or bush fires.

(iv) Tree raising and planting to replace food trees destroyed by the advance of settlement.

Faunal Reserves.-The Panel considered also the establishment of reserves to preserve the fauna of four habitats, Rain Forest and Snow Gums, Open Forest and Sandstone, Streams and Swamps, Mallee and Mulga. It awaits information of the available Crown Lands and the report of a Committee set up by the Department of Conservation on the Macquarie Marshes as a breeding ground for birds.

Perhaps no better comment upon this Act can be given than the words of Mr. David G. Stead, the founder of the Wild Life Preservation Society of Australia, quoted in "Australian Wild Life" :-

"The passing of the Act is an immense step forward towards the realization of the ideals of what I might term the wild life preservationists. Its implementation will put great heart into many people-those who love their Australia and want to preserve as much as possible of our beautiful and interesting wild creatures for the delectation and edification of future generations of Australia and of the world generally." 